\title{
Media Massa: Pencipta Industri Budaya Pencerahan yang Menipu Massa Studi Simulacra dan Hiperrealitas Film AVATAR
}

\author{
Yoyoh Hereyah \\ Universitas Mercubuana Jakarta \\ yoyohwibowo@yahoo.com
}

\section{ABSTRACT}

Globalization affects virtually all aspects of the society, including cultural aspects. Culture can be defined as values embraced by society or perception held by citizens of various things. Globalization as a symptom of the range of the values and culture of particular overlooks the world (so that it becomes 'world culture') have been seen since long. The Film is a form of mass media that bring values, cultures and ideologi of his creator. The concept of cultivations of cultural values is embedded through the ideas, stories, characters, special effects and the distribution of a film. Avatar upholds the value and ideologi from its producers.

Keywords: film studies, globalization, hegemony, hyperreality, simulacra

Globalisasi mempengaruhi hampir semua aspek yang ada di masyarakat, termasuk diantaranya aspek budaya. Kebudayaan dapat diartikan sebagai nilai-nilai (values) yang dianut oleh masyarakat ataupun persepsi yang dimiliki oleh warga masyarakat terhadap berbagai hal. Globalisasi sebagai sebuah gejala tersebarnya nilai-nilai dan budaya tertentu keseluruh dunia (sehingga menjadi budaya dunia atau world culture) telah terlihat semenjak lama. Cikal bakal dari persebaran budaya dunia ini dapat ditelusuri dari perjalanan para penjelajahan Eropa Barat ke berbagai tempat di dunia ini (Pye,1966).

Di sisi lain, interaksi cultural melalui perkembangan media massa (terutama televisi, film, music, dan transmisi berita dan olahraga internasional), memungkinkan kita dapat mengonsumsi dan mengalami gagasan dan pengalaman baru mengenai hal-hal yang melintasi be- ranekaragam budaya, misalnya dalam bidang fashion, literatur, dan makanan.

Dan berkah desa global ( Marshall Mc. Luhan, 1967: 36) telah menciptakan apa yang disebut dengan gaya hidup Global (The Global Life Style). Gaya hidup global yang dibawa oleh Media Massa ditandai dengan membanjirnya produk impor atau dari multinational corporation yang secara massal mengembangkan industrinya hampir di seluruh dunia, seperti pakaian, minuman, aksesoris, rumah tangga, parfum sampai pada jenis hiburan, musik, film, sinetron, lagu-lagu klasik dan popular, dalam bentuk ved yang memungkinkan orang dapat memutar sendiri dirumah-rumah. Produk produk tersebut telah mendorong warga desa global sebagai konsumen aktif, lebih besar sebagai pengguna produk-produk tersebut daripada harus menjadi pembuatnya. 
Terkait dengan hal di atas, salah satunya adalah film sebagai produk dan bentuk industri komunikasi massa yang memberi peranan tidak sedikit dalam 'the global deal market's tersebut. film Avatar, menjadi fenomenal untuk saat ini, dilihat dari jumlah penonton dan pemasukan uang yang melampaui film Titanic.

Film adalah salah satu produk dari budaya massa yang juga memenuhi ruang gerak manusia. Setiap tahunnya film selalu diproduksi secara massal untuk memenuhi kebutuhan khalayak yang sengaja dicipta oleh produsen agar tetap dapat menguasai produk-produk budaya massa. Avatar adalah salah satu film 'boom' dari segi perolehan finansial dan jumlah penonton. Ketertarikan para menonton melihat film tersebut, salaah satunya dipicu oleh special effect yang diciptakan oleh produsen, sebagai daya tarik yang kuat dari film tersebut. Produk budaya massa sebagai hasil produk kapitalis senantiasa menangkap hal-hal yang dapat memuaskan selera imaji penontonnya.

Dalam kondisi dunia yang demikian, budaya massa diproduksi besar-besaran berdasar perhitungan dagang belaka. Budaya massa mencakup seluruh produk terpakai atau barang konsumsi sebagai produk massal dan fashionable. Budaya massa tidak dapat lepas dari pola hiburan masyarakat. Istilah budaya massa sering dipertukarkan dengan budaya popular. Budaya massa tidak hanya bersifat hiburan, tetapi mencakup pula seluruh produk terpakai atau barang konsumsi sebagai produk massal dan fashionable yang formatnya terstandarisasi dan penyebaran dan penggunaannya bersifat luas (Ibrahim,1997:13)

Standar-standar yang diberlakukan untuk melayani kebutuhan konsumen secara cepat dan untuk alasan itulah industri budaya diterima dan munculnya lingkaran dari manipulasi dan kebutuhan dimana sebuah kesatuan sistem bertumbuh dengan kuat.

Konsep budaya massa menurut konsep barat bersifat komersial, menghibur, populer, mod- ern, merupakan paket, mempunyai audiens luas, dan dapat diperoleh secara 'demokratis' (Ibrahim,1997). Industri media massa dengan hasil produk-produknya disinyalir sebagai industri yang melahirkan kebudayaan pencerahan bagi masyarakat massa.

Perkembangan teknologi komunikasi amat memperluas lapangan budaya dengan memperlancar interaksi sosial yang tidak terikat pada ruang fisik. Dengan kata lain, deliveri budaya massa yang mengandalkan teknologi komunikasi memperlancar interaksi sosial mengatasi jarak fisik mengalami bentuk barunya. Adanya kemajuan dan perkembangan dalam bidang teknologi komunikasi memungkinkan media massa sebagai media budaya (Paul Willis, 1990 dalam James Lull, hlm.194)

Sejalan dengan pemikiran Paul Willis, Theodor Adorno (1903-1969) dan Max Horkheimer (1895-1973), yang berpendapat dalam bukunya "The Culture Industry: Enlightenment as Mass Deception," menjelaskan tentang budaya industri yang diciptakan media sebagai budaya pencerahan bagi massa. 'the culture industry claims to serve the consumers' needs for entertainment, and is delivering what the consumer wants... Culture industries may cultivate false needs; that is, needs created and satisfied by capitalism".

Dalam pengertian keduanya, budaya popular adalah serupa dengan sebuah pabrik yang memproduksi barang standar budaya, kenikmatan yang mudah tersedia melali konsumsi budaya populer membuat orang patuh dan tidak protes, tidak peduli apakah keadaan ekonomi mereka sulit. Budaya industri memunculkan dan menumbuhkan kebutuhan palsu, yaitu kebutuhan dan kepuasan yang dibuat oleh kapitalisme.

Di bawah monopoli, semua kebudayaan massa adalah identik, kekerasanya menjadi lebih terbuka sehingga kekuasaanya berkembang. Reproduksi tertentu adalah keniscayaan bahwa kebutuhan-kebutuhan identik perlu untuk 
dipuaskan dengan barang-barang yang identik. Sebagai contoh film-film dan radio tidak butuh lagi berpretensi sebagai seni.

Media terutama media massa adalah agen kebudayaan yang penting, mekanisme kerja media telah mengelola fakta menjadi berita yang memang telah diharapkan, media bukan hanya mempresentasikan realitas, ia juga memproduksinya. Bila berita adalah fakta plus makna, maka media telah mengubah fakta menjadi fakta yang lebih kuat daya persuasinya kepada masyarakat. Mereka merekayasa citra dari bahan data fakta ini secara kreatif menjadi citra yang kaya pesan, kenikmatan dan makna.

Tidaklah mengherankan bila massa ini kerap disebut 'the era of imagology'. Ketika citra menjadi lebih penting dari realitas empiriknya. Seperti kita maklumi, realitas citra tidak menginduk pada realitas empirik tetapi pada realitas simboliknya. Itulah kenapa pebisnis yang sukses ditayangkan dalam media massa bergaya dengan mobil BMW, yatch, heli atau bahkan jet pribadi mereka. Mereka inilah yang sering disebut selebritis. Dan, selebritis adalah ciptaan media. (Ibrahim, 1997: 85)

Film dalam kerangka yang sama juga melakukan 'imagology' bagi penontonnya. Ketika citra menjadi lebih penting dari realitas sesungguhnya. Film Avatar menawarkan 'imamology' tertentu kepada penonton, sehingga penonton tidak bisa lagi melihat mana yang imagi dan realitas sesungguhnya.

Kita mengenal jarak realitas empiric dan realitas mimpi yang dijembatani oleh media. Sejalan dengan pemikiran Baudrillard tentang teori hyper-reality dan simulation. Konsep ini sepenuhnya mengacu pada kondisi realitas budaya yang virtual ataupun artificial di dalam era berbagai bentuk simulasi (penggambaran dengan peniruan). Simulasi itulah yang mencitrakan sebuah realitas yang pada hakikatnya tidak senyata realitas yang sesungguhnya. Realitas yang "tidak sesungguhnya" tetapi di- citrakan sebagai realitas yang mendeterminasi kesadaran "kita" itulah yang disebut dengan realitas semu (hyper-reality). Realitas ini tampil melalui media-media yang menjadi "kiblat" utama masyarakat massa.

Melalui media realitas-realitas dikonstruk dan ditampilkan dengan simulators, dan pada gilirannya menggugus menjadi gugusan-gugusan imaji yang "menuntun" manusia modern pada kesadaran yang ditampilkan oleh simulator-simulator tersebut, inilah yang disebut gugusan simulacra. Simulator-simulator itu antara lain muncul dalam bentuk iklan, film, cybernetics, kuis, sinetron, dan lain-lain yang tampil dalam TV atau media lain yang mengobrak kepuasan fashion,food, dan funs. (Jean Baudrillard, "Simulacra and Simulations", dalam Jean Baudrillard, Selected Writings, ed. By Mark Poster (Cambgride: Polity Press, 1988) hal:166).

Indonesia, merupakan negara dengan nilainilai dunia ketiga, yang dalam konteks struktur internasional disebut negara periphery. Arus informasi dari negara-negara pusat, khususnya Amerika, telah melaju dengan cepat ke Indonesia, bukan hanya dalam bentuk kegiatan perekonomian sekaligus juga budaya. Penyebaran budaya dari negara 'core' sangat terasa, terutama dengan adanya tayangan film dan media televisi. Hal ini mempengaruhi budaya yang diterima masyarakat melalui media massa seperti media televisi, film, media cetak, radio yang sedikit banyak bisa berpotensi mengubah perilaku dan persepsi masyarakat terhadap sesuatu nilai atau budaya yang selama ini dipegang teguh.

Media massa di Indonesia sebagai alat yang memungkinkan penyebaran nilai, ideologi dan budaya sudah dikendalikan oleh kekuatan besar sebagai dampak globalisasi berbagai bidang kehidupan yang mau tidak mau harus dihadapi. Media pencerahan yang didengungkan menjadi adagium yang kontras dengan kenyataan.

Fenomena 'boomingnya' film avatar termasuk di Indonesia mengindikasikan adanya pe- 
nyitiran nilai, budaya dan ideologi yang ingin ditanamkan oleh produsen film tersebut. Fungsi media massa yang mencerdaskan sudah terkalahkan dengan ideologi kapitalis pengusaha media.

Berangkat dari latar belakang tersebut, yang harus dicermati dalam hal ini adalah permasalahan bagaimana peran media massa film dalam penciptaan industri kebudayaan pencerahaan sebagai penipuan massa. Ini penting mengingat bahwa media massa film sebagai pencipta industri kebudayaan pencerahan dan di sisi yang lain, film berperan penting dalam penciptaan industri kebudayaan pencerahan yang melakukan penipuan massa melalui proses hegemoni, ideologi, dan simulacra sehingga terjadi krisis identitas karakter bangsa.

\section{KERANGKA PEMIKIRAN}

James Lull menjelaskan tiga konsep dalam analisis kajian kritis dan pendekatan cultural yaitu ideologi, kesadaran, dan hegemoni. Ideologi merupakan sistim pengetahuan yang berkaitan dengan pencapaian tujuan dan kepentingan tertentu, Dan menggunakan symbol untuk hadir ditengah-tengah masyarakat. Ideologi berkaitan dengan sistem imaji, yang dapat diuraikan sebagai berikut: Aspek Ideasional disini berkaitan dengan unsure (morphem), organisasi aturan kebahasaan dimana ideologi dihadirkan. Aspek mediasional yang meliputi aspek teknologi dan interaksi. Aspek teknologi berkaitan dengan media yang digunakan dalam menyampaikan ideologi. Jadi disini berkaitan dengan pendekatan mediated dalam proses komunikasi.

Kesadaran adalah melihat bagaimana karakteristik media menentukan persepsi khalayak. Maka disini proses kesadaran berkaitan dengan jenis medium. Pengaruh media yang sangat kuat sehingga siapa pun yang mengendalikan media berarti mereka yang memiliki kemampuan dalam mempengaruhi kesadaran. Dalam kondisi kehidupan masyarakat yang masyarakat. Bahwa era media telah membuat persoalan tempat menjadi tidak berarti. Kehadiran media, juga berkaitan dengan nilai-nilai budaya tertentu. Bagaimana masyarakat mempersepsi dan member makna terhadap 'sesuatu', teknologi media ikut dipengaruhi nilai nilai yang telah ada disana. Demiian pulsa kehadiran teknologi media ikut membentuk budaya baru bagi suatu masyarakat.

Hegemoni berkaitan dengan kemampuan pengetahuan dalam rangka melakukan pendudukan secara halus, di mana pihak yang ditundukkan menerima hal itu seolah-olah sebagai suatu yang wajar. Terdapat banyak fenomena hegemoni dalam keseharian sebagai akibat proses komunikasi, hegemoni sangat berkaitan dengan aspek ideologi dan kesadaran hegemoni menandakan tampilnya suatu ideologi dominan tertentu yang mampu mempengaruhi kesadaran orang banyak. Media di antaranya melakukan peran dalam proses membangun hegemoni ini. Ideologi, kesadaran dan hegemon membentuk pola hubungan median dengan massa.

Menurut James Lull (1998:2) "manipulasi yang dilakukan tanpa henti terhadap informasi dan citra publik mengkonstruksikan suatu ideologi dominan yang kuat yang membantu menopang kepentingan material dan kultural para penciptanya. Para pembuat ideologi yang dominan menjadi suatu 'elite informasi'. Kekuasaan dan dominasi mereka bergerak dari kemampuan mereka untuk mengartikulasikan kepada masyarakat sistem ide yang lebih mereka sukai. Ideologi mempunyai kekuatan apabila dapat dilambangkan dan dikomunikasikan. Dalam hal ini ideologi kapitalisme ditransmisikan dengan cara "tatabahasa produksi" (grammar of production) yang melaluinya media menguniversalkan suatu gaya hidup.

Raymond Williams menyebut ideologi sebagai himpunan ide-ide yang muncul dari seperangkat kepentingan material tertentu, atau secara lebih luas dari sebuah kelas atau kelompok tertentu. Hal tersebut ditegaskan oleh Stuart 
Hall yang berpendapat bahwa ideologi, bukan hanya otoritas ekonomi, berfungsi membentuk dan mempertahankan pembagian kelas dalam masyarakat kapitalis.

\section{HEGEMONI ANTONIO GRAMSCI}

Menurut teori Gramsci mengenai Hegemoni, media massa adalah alat yang digunakan elit yang berkuasa untuk melestarikan, kekuasaan, kekayaan dan status mereka (dengan mempopulerkan) falsafah, kebudayaan dan moralitas mereka sendiri. Para pemilik dan pengelola industri media dapat memproduksi dan mereproduksi isi, dan nada dari ide-ide yang menguntungkan mereka dengan jauh lebih mudah ketimbang kelompok sosial lain (Ibrahim, 1997). Hegemoni sebenarnya sama dengan dominasi yang berarti penaklukan. Bedanya, dominasi merupakan penaklukan secara keras dengan menggunakan kekuatan koersi (memaksa) seperti pengadilan, kepolisian, dan militer. Sementara hegemoni adalah penaklukan secara halus yang menghasilkan keputusan kelas (yang sebenarnya ditindas) lewat kekuatan ideologis seperti pendidikan dan media massa.

Hegemoni merupakan terminology penting yang digunakan Gramsci (1971), yang diartikan sebagai cara yang kuat atau kehadiran di manamana (omnipresence) sesuatu secara penuh. Lebih jauh teori ini menekankan bahwa dalam lapangan sosial ada pertarungan untuk memperebutkan penerimaan publik. Karena pengalaman sosial kelompok subordinat (bisa kelas,gender, ras, umur dan sebagainya) berbeda dengan ideologi dan kebenarannya tersebut agar diterima tanpa perlawanan. Salah satu strategi kunci dalam hegemoni adalah nalar awam (common sense). Jika idea atau gagasan dari kelompok dominan/ berkuasa diterima sebagai common sense (jadi tidak didasarkan pada kelas sosial), kemudian ideologi itu diterima, maka hegemoni telah terjadi.

Hegemoni bekerja melalui konsensus daripada upaya penindasan satu kelompok terhadap kelompok lain. Salah satu kekuatan hegemoni adalah bagaimana ia menciptakan cara berpikir atau wacanan tertentu yang dominan, yang dinggap benar, sementara wacana lain dianggap salah. Ada satu nilai atau consensus yang dianggap memang benar, sehingga ketika ada cara pandang atau wacana lain dianggap tidak benar. Media di sini secara tidak sengaja dapat menjadi alat bagaimana nilai-nilai atau wacana yang dipandang dominan itu disebarkan dan meresap dalam benak khalayak sehingga menjadi konsensus bersama.

Menurut Gramsci, dalam hegemoni, media massa adalah alat yang digunakan elit berkuasa untuk melestarikan kekuasaan, kekayaan dan status mereka dengan mempopulerkan falsafah, kebudayaan dan moralitas mereka sendiri. Ideologi yang di-mediamassa-kan dibenarkan dan diperkuat oleh sebuah sistem keagenan yang saling terkait dan efektif dalam mendistribusikan informasi dan praktek-praktek sosial yang sudah dianggap semestinya, yang merembesi segala aspek realitas sosial dan budaya. Menurut seorang ahli sosial kebangsaan Inggris, Philip Elliot (dalam Lull, 1998:34), dampak media massa yang paling dahsyat adalah cara mereka memengaruhi audiens secara pelan dan halus (subtly) untuk mempersepsi peran sosial dan aktivitas pribadi yang rutin.

\section{SIMULACRA BAUDRILLARD}

Filosofi Baudrillard terpusat pada dua konsep "hyperreality" dan "simulation". Terminology ini mengacu pada alam yang tidak nyata dan khayal dalam kebudayaan kontemporer pada zaman komunikasi massa dan konsumsi massa. Baudrillard menggambarkan realitas melalui empat tahap: (1) it (image) is the reflection of the basic reality, (2) it makes and pervert a basic reality, (3) it makes the absence of the basic reality, dan (4) it bears on relation on any reality whatever: it is its own pure simulacrum. Dari keempat tahap itu, tahap kedua adalah 
yang paling penting bahwa image bahkan bisa mengelabui kita sehingga kita tidak sadar lagi akan ketidakhadirannya. Gambaran dalam media massa dan cyber seperti televisi, internet tidak lagi kita pahami dalam kerangka semiotic signifier dan signified tanda-petanda

Jarak keduanya lenyap, sehingga yang tinggal hanyalah sebuah pengalaman langsung. Artinya, kita seolah-olah tidak senang menghadapi image atau gambaran tentang "realitas" itu sendiri. Inilah yang disebut Baudrillard dengan istilah immediate, the unsignified atau simulacrum yang berarti tiruan, imitasi, tidak nyata, tidak sesungguhnya.

Konsep Baudrillard mengenai simulasi adalah tentang penciptaan kenyataan melalui model konseptual atau sesuatu yang berhubungan dengan "mitos" yang tidak dapat dilihat kebenaran dan kenyataannya. Model ini menjadi faktor penentu pandangan kita tentang kenyataan. Segala yang dapat menarik minat manusia - seperti seni, rumah, kebutuhan rumah tangga dan lainya - ditayangkan melalui berbagai media dengan model-model yang ideal, di sinilah batas antara simulasi dan kenyataan menjadi tercampur aduk sehingga menciptakan hyperreality di mana yang nyata dan yang tidak nyata menjadi tidak jelas.

Hiperealitas menciptakan satu kondisi yang di dalamnya kepalsuan berbaur dengan keaslian; masa lalu berbaur masa kini; fakta bersimpang siur dengan rekayasa; tanda melebur dengan realitas; dusta bersenyawa dengan kebenaran. Kategori-kategori kebenaran, kepalsuan, keaslian, isu, realitas seakan-akan tidak berlaku lagi di dalam dunia seperti itu. Baudrillard menerima konsekuensi radikal tentang sesuatu yang dilihatnya merasuk dalam 'kode' di masa modern ini. Kode ini jelas terkait dengan komputerisasi dan digitalisasi, kode ini bisa mem-bypass sesuatu yang real dan membuka kesempatan bagi munculnya realitas yang disebut Baudrillard sebagai hyperreality." (Lechte, 2001, hlm. 352)
Keadaan dari hiperrealitas ini membuat masyarakat modern ini menjadi berlebihan dalam pola mengkonsumsi sesuatu yang tidak jelas esensinya. Kebanyakan dari masyarakat mengkonsumsi bukan karena kebutuhan ekonominya melainkan karena pengaruh model model dari simulasi yang menyebabkan gaya hidup masyarakat menjadi berbeda. Mereka jadi lebih perhatian terhadap gaya hidup dan nilai yang mereka junjung tinggi.

\section{PEMBAHASAN}

Studi simulacra dan hiperrealitas dalam film AVATAR berguna dalam pembongkaran peran media massa film sebagai pencipta industri kebudayaan pencerahan yang melakukan penipuan massa melalui proses hegemoni, ideologi dan simulacra sehingga terjadi krisis identitas karakter bangsa.

Avatar adalah film yang menceritakan tentang sebuah satelit sebesar bumi yang dihuni oleh bangsa $\mathrm{Na}$ 'vi yang peradabannya mulai diusik oleh manusia. Bangsa Na'vi adalah mahluk primitive yang sekilas mirip manusia, hanya saja mereka bertubuh besar, berwarna biru dan memiliki ekor. Avatar merupakan program pembuatan mahluk yang mirip dengan suku Na'vi sehingga memungkinkan Jake untuk bisa berjalan kembali. Saat mempelajari kehidupan bangsa Na'vi, Jake menemukan berbagai macam hal yang menakjubkan baik dari kebudayaan bangsa Na'vi itu sendiri maupun dari keindahan hutan Pandora. "Avatar" menceritakan perang untuk mempertahankan hidup antara kaum Na'vi yang tinggal di hutan, melawan operasi pertambangan kolonial di planet mereka.

Terjebak di antara dua kubu yang bertikai memang tak pernah menyenangkan dan itulah yang dialami Jake Sully (Sam Worthington) saat ia setuju untuk dikirim ke Pandora. Di planet asing yang dihuni berbagai mahluk ini Jake yang semula berharap bisa memulai hidup baru malah terlibat masalah pelik yang meng- 
haruskan memilih pihak. Jake adalah mantan marinir yang mengalami luka parah dalam sebuah pertempuran di bumi. Akibatnya kaki Jake mengalami kelumpuhan total. Ada satu harapan untuk Jake. Jika ia mengikuti program Avatar dan dikirim ke planet Pandora maka ia akan kembali bisa berjalan seperti sedia kala meski konsekuensinya Jake akan menggunakan 'tubuh baru'. Agar memungkinkan buat manusia untuk hidup di Pandora maka mereka dibuatkan satu tubuh buatan dan pikiran para manusia ini akan ditanamkan ke dalam tubuh yang disebut Avatar ini sehingga Avatar ini seolah-olah adalah tubuh mereka sendiri. Tugas Jake adalah menjadi pemandu bagi beberapa manusia yang menggunakan tubuh Avatar untuk mencari sumber mineral baru untuk kepentingan industri di bumi. Di tengah perjalanan, Jake bertemu Neytiri (Zoe Saldana), bangsa Na'vi penghuni planet Pandora. Seiring berjalannya waktu Jake pun jatuh cinta pada Neytiri. Berawal dari cinta inilah Jake lantas menghadapi dilema antara melanjutkan misinya mengeksplorasi Pandora atau membela kaum Na'vi melindungi Pandora. Secara keseluruhan film ini amat menarik.Kalaupun ada kekurangan yang terasa sebenarnya adalah ide cerita yang terasa generik. Kalau mau jujur, ide dasar cerita ini tak jauh beda dengan beberapa film yang mencoba mengungkap masalah yang sama seperti film The Last Samurai dan Dances With Wolves.

\section{DUNIA HIPERREALITAS}

Film adalah salah satu bentuk media massa yang membawa nilai, budaya, dan ideologi penciptanya. Konsep penanaman nilai-nilai budaya dilakukan melalui pemilihan dan ide, cerita, penokohan, special effect, hingga distribusi produk film yang dihasilkan. Avatar sebuah film yang mengusung nilai dan ideologi di mana film itu dibuat. Sukses film Avatar ditandai dengan suksesnya film tersebut mendulang 'fulus' di berbagai negara termasuk di Indonesia.
Berdasarkan catatan $\mathrm{CNN}$, sebuah situs penggemar film Avatar di Amerika Utara menerima 1.000 posting terkait depresi penonton. "Setelah menonton Avatar, saya benar-benar depresi saat bangun di dunia nyata, saya berbagi cerita dengan orang lain untuk mengurangi depresi ini" "saya ingin menjadi bagian suku Na'vi” (Harian Sindo, Rabu 13 januari 2010)

Kehidupan saat ini ditandai dengan simulasi. Proses ini mengarah kepada penciptaan simulacra atau "reproduksi objek atau peristiwa". Dengan kaburnya perbedaan antara tanda dan realitas, maka semakin sukar mengenali yang tulen dari barang tiruan. Masyarakat saat ini sudah tidak lagi didominasi oleh produksi tetapi lebih didominasi oleh "media, model sibernetika dan sistem pengemudian, komputer, pemrosesan informasi, industri hiburan dan pengetahuan, dan lainya". Kita menjadi budak simulasi," yang membentuk sistem lingkaran yang tak berujung pangkal. Cerita Avatar yang disuguhkan mengharubiru, menggembirakan dan menghibur tidak jauh berbeda dengan sinetron atau drama sejenisnya dapat melarut pula perasaan dari pemirsa.

Film Avatar yang disajikan memainkan peranan yang cukup dominan untuk mengharu biru penonton dengan special effect yang disajikan. Bila dikaitkan dengan konsep Baudillard inilah lukisan dari kehidupan saat ini yaitu terbentuknya hiperrealitas (realitas semu). Tidak ada lagi realitas yang ada hanyalah hiperrealitas. Dampak yang dihasilkan dari hiperrealitas adalah adanya kepercayaan masyarakat terhadap kenyataan yang sebenarnya bukan kenyataan. Pembodohan atas realitas ini dapat menghasilkan pola budaya yang mudah meniru (imitasi) apa yang dilihatnya sebagai sebuah kenyataan yang direalisasikan dalam kehidupan sehari-hari. Selain itu, terbentuk pula pola pikir yang serba instan, membentuk manusia yang segala sesuatunya ingin cepat tersedia. 
Adanya realitas yang tersajikan dengan citra yang menghibur itu dapat menumbuhkan semangat dalam masyarakat untuk berbuat demi kemanusiaan, namun komoditas atas kepentingan keuntungan yang tersaji dari bingkai realitas dalam media mengalahkan nilai, makna yang bermanfaat bagi masyarakat. Massa digiring pada suatu pemahaman, adanya identifikasi yang sama dan penyeragaman nilai.

Mengacu pada konsep Luhan dan Gramsci tentang ideologi, hegemoni, dan dominasi, media massa adalah alat yang digunakan elit berkuasa untuk melestarikan kekuasaan, kekayaan, dan status mereka dengan mempopulerkan falsafah, kebudayaan dan moralitas mereka sendiri.

Dalam hal ini senada dengan itu, proses pembuat film juga mengacu pada hal yang sama, adanya unsure ideologi, hegemoni, dan dominasi dari para pemilik dan pengelola industri media dalam mengontrol dan menguasai kelompok sosial lainnya serta melakukan 'pemaksaan secara halus budaya mereka terhadap kelompok sosial lain dengan memproduksi dan memreproduksi isi, dan nada dari ide-ide yang menguntungkan mereka dengan jauh lebih mudah melalui caracara persuasi dengan dalih memenuhi kebutuhan merka dengan konsep-konsep berdasar pertimbangan kelompok sosial yang dominan.

Secara perlahan tetapi pasti, para penonton terlena dengan segala kemudahan hidup, budaya konsumsi yang serba instan membuat mereka lupa bahwa hidup yang mereka hadapi mulai kabur dan tenggelam dalam realitas semu. Film adalah hasil rekayasa manusia, produksi film hasil karya yang mengharuskan padat modal, padat teknologi, dan sumber daya manusia yang terlatih. Modal besar diperlukan untuk membuat sebuah film yang berdurasi puluhan menit tersebut. Ketika berbicara tentang film dan teknologi canggihnya, maka kita akan berkiblat ke negara pemilik teknologi tersebut, AS dan negara daratan Eropa.
Media termasuk juga film Avatar seakan menjadi alat industri yang memberi pencerahan kepada massa dengan memberikan ragam informasi dan media yang disodorkan kepada mereka. Perlu pula diwaspadai bahwa pemilik tetap menjadi penentu isi dari media tersebut. Jelas sekali isi sudah dikonstruksi sesuai dengan ideologi mereka, yaitu ideologi Kapitalis. Rekayasa, penyeragaman acara menjadi hal yang dapat kita rasakan dalam sistem yang seperti ini. Alihalih memberi pencerahan, media menjadi alat penipuan massa dan menjadi pelaku pembodohan yang massif terhadap masyarakat. Masyarakat dilenakan dengan sajian media yang dangkal dan artifisial bahkan mungkin mustahil ada dalam realitas sesungguhnya.

Avatar, salah satu contoh film yang mengusung nilai-nilai kapitalis. Penonton dilenakan dengan imaji yang membius dan ide cerita yang fantastis. Yang penting penonton puas dengan sajian film tersebut, tanpa harus mengerutkan kening dan berpayah-payah memikirkan isi film tersebut.

Di Indonesia saat ini film didominasi oleh film-film barat termasuk penayangan Avatar secara serentak di tanah air. Hal ini tidak lepas dari sistem kapitalis yang melanda industri perfilman, ketika Indonesia memasuki arus global. Ada standar-standar khusus yang diberlakukan dalam sistem tersebut. semisal standar gedungnya, ide ceritanya, sistem manajemennya.

Dalam kondisi yang seperti inilah, mudah bagi bangsa lain untuk melakukan penetrasi hegemoni budaya dan ideologi kepada negara Indonesia. Hal ini ditengarai salah satunya dengan dikuasainya sistem perfilman Indonesia oleh negara pemasok film barat. Mudah bagi mereka untuk mendikte sesuai dengan kehendak dan selera mereka, selera ideologi kapitalis global.

Krisis identitas karakter bangsa suatu yang bukan mustahil terjadi saat ini di Indonesia. Adakah budaya Indonesia yang dimiliki Indonesia saat ini? Nilai dan karakter suatu bangsa 
akan tercermin dari budaya yang mereka usung dalam berbangsa dan bernegara. Indonesia sedang mengalami dilema dan krisis nilai saat ini.

Film sebagai bentuk penyedia hiburan memang ampuh untuk menghilangkan segala kepenatan hidup, namun film pun dapat menjadi sebuah penanda terjadinya krisis nilai suatu bangsa.

\section{KESIMPULAN}

Mengacu pada konsep McLuhan dan Antonio Gramsci tentang ideologi, hegemoni dan dominasi, media massa adalah alat yang digunakan elit berkuasa untuk melestarikan kekuasaan, kekayaan dan status mereka dengan mempopulerkan falsafah, kebudayaan dan moralitas mereka sendiri. Ideologi merupakan sistem pengetahuan yang berkaitan dengan pencapaian tujuan dan kepentingan tertentu dan menggunakan symbol untuk hadir di tengah tengah masyarakat, kesadaran adalah melihat bagaimana karakteristik media menentukan persepsi khalayak. Maka di sini proses kesadaran berkaitan dengan jenis medium. Pengaruh media yang sangat kuat sehingga siapapun yang mengendalikan media berarti memiliki kemampuan dalam mempengaruhi kesadaran. Hegemoni berkaitan dengan kemampuan pengetahuan dalam rangka melakukan penundukan secara halus, di mana pihak yang ditundukkan menerima hal itu seolah olah sebagai sesuatu yang wajar. Terdapat banyak fenomena hegemoni dalam keseharian sebagai akibat proses komunikasi, hegemoni sangat berkaitan dengan aspek ideologi dan kesadaran.

Dalam hal ini senada dengan itu, proses pembuatan film juga mengacu pada hal yang sama, adanya unsur ideologi, hegemoni dan dominasi dari para pemilik dan pengelola industri media dalam mengontrol dan menguasai kelompok sosial lain. Caranya dengan memproduksi dan mereproduksi isi, nada dari ide ide yang menguntungkan mereka dengan jauh lebih mudah melalui cara-cara persuasui dengan dalih yang memenuhi kebutuhan merka dengan konsepkonsep berdasar pertimbangan kelompok sosial yang dominan.

Globalisasi saat ini memungkinkan industri media massa menciptakan kebudayaan massa dan menyampaikan pesan kepada massa dengan massifnya, dimana kebudayaan massa umumnya hanya mengakomodir selera rendah masyarakat massa. Ideologi kapitalis melakukan pelanggengan kekuasaaan terhadap massa dengan penyeragaman dan homogenitas acara (identik). Akhirnya kebudayaan massa hanya mengakomodasi selera rendah masyarakat massa.

Film sebagai bagian dari media massa dan produk budaya massa, memiliki pengaruh yang kuat dalam melahirkan masyarakat yang pasif. Lewat sajian film Avatar, terjadinya hegemoni, dominasi dan ideologi kapitalis dapat terlihat dari imaji yang sengaja dilakukan produsen untuk mengiring massa pada satu produk budaya massa. Isi media menyajikan simulacra, kebutuhan semu dan menciptakan dunia semu (hiperrealitas). Film Avatar menawarkan sesuatu yang sebetulnya tidak ada dalam dunia nyata namun disukai oleh penonton. Hegemoni terjadi atas kuasa dominasi pemilik modal terhadap penonton dengan mengebiri kebebasan berimajinasi. Kontrol sudah dilakukan oleh pihak produsen dengan pemilihan setting, cerita, special effect hingga jalur pendistribusian film tersebut. Penonton dan penikmat film dilenakan dengan segala pengaturan yang dilakukan oleh para pemodal industri media.

Dalam situasi yang seperti itu krisis identitas karakter tercipta karena masyarakat menerima ideologi, nilai dan budaya yang disuguhkan media massa (budaya barat) dan tidak memahami lagi, realitas media dan realitas sesungguhnya bahwa sebenarnya industri media massa menjadi kendaraan bagi budaya pencerahan semu yang menipu massa yang menyebabkan krisis identitas karakter bangsa. 
Media Massa: Pencipta Industri Budaya Pencerahan yang Menipu Massa Studi Simulacra dan Hiperrealitas film AVATAR

\section{DAFTAR PUSTAKA}

Adorno, Theodor dan Max Horkheimer (1944). The Culture Industry: Enlightenment as Mass Deception (versi daring bisa diakses di: http://www.marxists.org/ref erence/archive/adorno/1944/culture-in dustry.htm)

Agger, Ben. (1992). Cultural Studies as A Criti cal Theory. London: Palmer.

---. (1992). Teori Sosial Kritis: Kritik, Penerapan dan Implikasinya. Yogyakarta: Kreasi Wacana.

Artz, Lee dan Yahya R. Kamalipour. (Tim editor). (2003). The Globalization of Corporate Media Hegemony. Albany: State University of New York Press.

Baudrillard, Jean dan Marie Maclean. (1985). "The Masses: The Implossion of the Social in the Media" dalam jurnal New Literary History Vol. 16, No. 3, On Writing Histories of Literature (Spring, 1985), hlm. 577589.

Baudrillard, Jean. (1988). "Simulacra and Simulations," dalam Mark Poster (editor). Jean Baudrillard, Selected Writtings, Cambridge: Polity Press

Gitlin, Todd. (1979). "Prime time ideologi: The Hegemonic process in Television", dalam Horace Newcomb (ed). (1994). Television: The Critical View. Fifth edition. New York: Oxford University Press.

Ibrahim, Idi Subandy. (1997). Lifestyle Ectasy:
Kebudayaan Pop dalam Masyarakat Komunitas Indonesia. Yogyakarta: Jalasutra.

Lechte, John. (2001). 50 Filsuf Kontemporer: Dari Strukturalisme sampai Postmodernitas. Yogyakarta: Kanisius.

Lull, James. (1998). Media Komunikasi Kebudayaan, Suatu Pendekatan Global. Jakarta: Yayasan Obor.

Pye. Lucian W. (1966). Aspects of Political Development. Boston: Little, Brown, and Co.

Ritzer, George. (2006). Mengkonsumsi Kehampaan di Era Globalisasi. Yogyakarta: Universitas Atmajaya.

Sutrisno, Mudji, dkk. (tim editor). (2007). Cultural Studies: Tantangan bagi Teori-Teori Besar Kebudayaan. Depok: Koekoesan.

Non Buku:

Simons, Gary. (2006). Tanpa tahun. "Stimulating Stimulation," bisa diakses di

http://www.google.co.id/url? sa=t\&rct=j\&q= \&esrc $=\mathrm{s} \&$ source $=$ web $\& \mathrm{~cd}=2 \& \mathrm{ved}=0 \mathrm{C}$ EcQFjAB\&url=http\%3A\%2F\%2Fohas sta.org\%2Fwordfiles $\% 2 \mathrm{~F}$ conference 20 06\%2FStimulating\%2520Simulations. doc\&ei=pWgoUKjwO4mIrAeM_oH4Dg \&usg=AFQjCNG53feZk7OjUzwtIbj1G4 $\mathrm{AaD} 15 \mathrm{sCg}$

http://id.wikipedia.org/w/index.php?title=Glob alisasi\&action $=$ edit

(http://gosipboo.blogspot.com/2009/12/resensifilm-avatar.html) 